\title{
Mentoring Undergraduates: Professors Strategically Guiding the Next Generation of Professionals*
}

\author{
Edgar C. J. Long \\ Central Michigan University \\ Jessica Fish \\ Purdue University, Calumet \\ Lee Kuhn \\ Syracuse University \\ John Sowders \\ University of Wisconsin- Stout
}

\begin{abstract}
* Please address all correspondence to: Dr. Edgar Long, Department of Human Environmental Studies, Central Michigan University, 412D EHS Building, Mt. Pleasant, MI 48859, Phone: (989) 774-2379; Fax: (989) 774-2435; Email: longlec@cmich.edu.
\end{abstract}

\begin{abstract}
One faculty member and three former undergraduate mentees discuss the development of their mentoring relationship. This paper is one description of how a mentoring relationship develops over time and how it benefits students, faculty and the university. Mentoring is not defined as how faculty impact students, but as an interdependent relationship, each person influencing, and being influenced by the other. The paper concludes by examining some of the systemic, institutional challenges that keep mentoring from happening and describes some future research that needs to be undertaken.
\end{abstract}

Keywords: Faculty, Mentoring, Undergraduates,

My own interest in mentoring began during my first year of college. As a naïve freshman, I was surprised when a faculty member approached me after a large lecture class and mentioned that he had read my last assignment and thought I had a lot of "academic ability." I suggested he must have confused me with another more promising student. Upon his insistence, the conversation continued as did the relationship. Thirty years later, the fact that his interest focused on my person, rather than my understanding of a component of his course, still motivates me to pursue mentoring relationships with undergraduate students.

During my freshman year I spent many hours in that professor's office, asking questions about classes, majors, careers, and further education. The earliest discussions dealt with issues focused mostly on my educational pursuits, but over time, the discussions evolved, often into issues of a more personal nature. One day, while sitting in his office, I said to myself, "I want to do what he does." My interest in higher education, being a faculty member, and positively impacting the 
lives of students, began that semester as a result of that relationship. When I think about the significant impact professors can have on the lives of their undergraduate students I often think of that professor and his investment in students outside of the classroom. My interaction with him, our relationship, has been life changing educationally, professionally, and personally. Until his untimely death ten years ago, Dr. Palfreyman would regularly call me asking about, my personal and professional goals, how my family was doing, what scholarship I currently was working on, and whether or not he could help me in any way. Before he died, the relationship came full circle. In the completion of his doctorate, I had the privilege of being his mentor as he completed the statistical analyses for a dissertation on the not surprising topic of "mentoring."

This paper describes the mentoring relationship of one faculty member with three undergraduate mentees and highlights some of the beneficial outcomes for faculty and students. The description of mentoring here is not meant to be the best model to follow. It is one example of how a mentoring relationship develops over time and how it benefits students and faculty. The aim is to present a model and rationale for mentoring that will encourage faculty, students, and universities to be more strategic in developing these relationships. To that end, I have incorporated comments from three former protégés, hoping to provide a glimpse into our lived experience, and the reciprocal nature of mentor-mentee relationships. Each of my co-authors was asked a series of questions and then responded describing their experiences in relationships with any of their undergraduate mentors. Each of them is a first generation student. Jessica Fish graduated from Central Michigan University (CMU) in the spring of 2008 with a double major in Family Studies and Psychology. Currently, she is a graduate student in the Marriage and Family Therapy (MFT) program at Purdue University, Calumet. John Sowders graduated from CMU in 2008, with a double major in Child Development and Psychology. John is a graduating MFT student at the University of Wisconsin, Stout and has been admitted into the MFT Ph.D. program at the University of Louisiana, Monroe. Lee Kuhn graduated from CMU in the spring of 2009, with a double major in Family Studies and Psychology. Lee is in the graduate MFT Program at Syracuse University. Throughout the paper each of these students adds their voice and describes their experience being mentored.

\section{Mentoring Defined}

In the empirical literature, mentors are referred to as coaches, a mixture of good fathers and friends (Levinson, Darrow, Klein, Levinson, \& McKee, 1978). More recent definitions suggest that mentoring is a deep understanding and appreciation for the circumstances and unique abilities of a protégé that go beyond an interest in any single personal dimension. Cramer uses the Latin phrase "cura personalis", care for the entire person, to demonstrate the depth and scope of the mentoring relationship (Cramer \& Prentice-Dunn, 2007). The definitions in the literature seem to assume that mentoring is unidirectional, mentors influence mentees. This paper includes the voices of students and professor, highlighting the reciprocal nature of the dyad. Given the bidirectional 
impact of the mentoring relationship and the lack of a student voice in the literature, it seemed essential that students' voices be included in the discussion of mentoring.

In this paper, mentoring is limited to professors and undergraduate students. Although many faculty in academia are familiar with the mentoring relationships that develop between faculty and graduate students, few seem to understand or regularly develop protégé relationships with undergraduates. Even though studies highlight positive outcomes derived from mentoring, little is understood about faculty mentoring undergraduate students (Cramer, Prentice-Dunn, 2007). There is even some mentoring research that focuses on graduate students mentoring undergraduates (Evans, Perry, Kras, Gale, \& Campbell, 2009). The implicit assertion seems to be that undergraduate mentoring should be left to graduate students.

I had never even heard of faculty mentoring undergraduates until I was actually working with my mentor on a research project. Very few of my peers were aware of the wealth of educational opportunities one acquired through faculty mentorships, most of my peers didn't understand the benefits from this process. Initially, and even during my first couple of years of college, I thought that faculty were unavailable and uninterested. However, it's somewhat telling, most of the students I am in graduate school with now, had strong and lasting mentoring relationships with faculty while they were undergraduates. In retrospect, I realize there are faculty who are available and interested in developing these relationships with undergraduates (Jessica).

Given the positive outcomes in the mentoring research, overlooking undergraduates as mentees dilutes the significance and impact of the undergraduate educational experience. There is evidence to suggest that compared to non-mentored students, students who are mentored are better at problem solving, decision making, goal setting, making an effective transition to college, and overall they are happier with their educational experience (Cosgrove, 1986; Kardash, 2000).

Even though faculty mentoring has positive student outcomes, there is no discussion of the benefits that faculty, and even universities, might experience when professors mentor undergraduates. Part of the problem is that mentoring is defined as a unidirectional relationship. When mentoring is defined in this linear fashion, there is no need to examine the ways in which mentoring impacts professors or universities. The assumption seems to be that mentoring only impacts students.

There are several purposes for this paper on undergraduate mentoring. First and foremost, if students, faculty, and universities can benefit from these relationships then a clearer understanding of mentoring is justified. If faculty seldom mentor undergraduates, then a description of the experience of colleagues along with a better understanding of methods used to develop these relationships seems warranted. Finally, undergraduates themselves need to hear about the 
experiences of their peers and be aware of the benefits and possibilities derived from this component of the undergraduate experience.

\section{Types of Mentoring}

In the empirical literature several different types of mentoring are delineated (i.e., academic, youth, employee). Although all three types of mentoring have similarities, the focus of each type is unique. Academic mentoring focuses on academic adjustment, retention, and overall educational success (Johnson, 2007; Ragins, 2002). Youth mentoring highlights a relationship with youth at risk, attempting to deter risky youth behavior (DuBois \& Karcher, 2005). Mentoring employees is an attempt to facilitate career development and assist new entrants into the workplace, (Eby, 1997; Eby, Allen, Evans, Ng, \& DuBois, 2008). A meta-analysis of the mentoring research demonstrated that of all three types of mentoring, academic mentoring produced the strongest positive outcomes (Eby, Allen, Evans, Ng, \& DuBois, 2008).

Academic achievement, grade point average, school absence, drop out rates, satisfaction with the university academic experience, attitude towards the school, time spent on educational pursuits, and number of semesters to graduation were all related positively to academic mentoring (Crane, \& Prentice-Dunway, 2007). Given these positive academic outcomes, institutions would do well to be more strategic in developing mentoring relationships and rewarding faculty who engage in this endeavor.

On university campuses across the United States there is within one area of the university a purposeful and strategic focus on mentoring. Specifically, a concerted effort towards a high level of mentoring seems to be happening within athletic programs. In fact, faculty in the academy may have much to learn from athletic coaches on university campuses. Over the years I have been surprised at the level of care and concern athletic coaches demonstrate towards the "entire person." Legendary UCLA basketball coach, John Wooden recently published a book on mentoring, speaking about the power of mentoring and being mentored (Wooden, Yeager, \& Maxwell, 2009). As a mentor, Wooden set the bar high and was a role model of mentoring done with excellence. While coaches' primary motivation may be winning games, they do not limit their interest to an athlete's performance. My son in law, a university basketball coach, was in my office the other day. While he could only remember the names of a few of his former teachers, there was not one coach whose name he had forgotten. Although he had fewer coaches than teachers, he spoke about the level of concern his coaches had regarding his class attendance, study habits, exams, and grades, as well as his friendships, family, and extra-curricular activities. His teachers were interested in him pursuing history or literature; yet, few of them took many opportunities to ask him any questions beyond their disciplines. To be clear, I am not arguing that university athletic coaches are admirable models that academics should emulate. Justified and serious criticisms of university athletic programs and their negative impact on undergraduate educational outcomes and the aversive economic costs to universities have been made (Sperber, 2000). However, I do believe faculty might learn valuable lessons about mentoring from university coaches. What 
could happen in the academic world if professors showed the level of commitment to the academic interests of their students as athletic coaches demonstrate towards their athletes? If students were encouraged and pushed academically as athletes are in training for their sport, what level of academic growth and productivity could we see in students' lives?

I was familiar and often overwhelmed with the excessive challenges in the athletic world. I left college football as a sophomore, and moved to CMU after deciding to pursue more academically oriented goals. As a result of my interest in family therapy, my mentor challenged me to accept a very intense yet rewarding internship with juveniles who were on probation for substance abuse violations. During the third week of the internship I was drug testing juveniles in the local high school. My mentor found a way to challenge my under developed skills. When I met him I was very naïve as a student and person. He had a special gift to realize that I had potential and pushed me to achieve more. Through class work and independent research, I started to enhance the skills I needed to succeed in the professional world. I soaked in the two years I had with him and took advantage of every opportunity that arose to learn (John).

\section{The Mentoring Relationship}

The mentoring literature is clear, important personal characteristics impact the mentoring relationship. Mentors should be approachable, knowledgeable, willing, able to communicate care, good listeners, self disclosing, personable, empathic, and altruistic (Cramer et al., 2007). At the same time Cramer and colleagues (2007) go on to assert that a mentor should be a real person, dealing with the same types of issues as all human beings. Those comments by Cramer almost seem humorous. Can a person be empathic, a good listener, self disclosing, personable, and not at all concerned about how they might benefit from the mentoring relationship? The person described above does not sound like a "real person." It is important that faculty understand that one need not possess all of the qualities above to be a good mentor. Given the bi-directional nature of a mentoring relationship, it is not merely the personal characteristics of the mentor that are important. Students and faculty both bring personal characteristics to the relationship, and the characteristics of both impact the relationship. A good mentor with one person may only be an adequate mentor with another student. Mentoring is a relationship, and relationships are interdependent. Faculty impact, and are impacted by students. More important than the characteristics of either member of the dyad, is the quality of the interaction, the blending of the personality characteristics. The needs and goals of faculty and students combined create strong or weak mentoring relationships.

He was an open and caring individual which made it easy for me to form a relationship with him. He treated me as an equal in a relationship that is typically hierarchal in nature and that made a big difference in how invested I became in the relationship. My mentor was the first professor to introduce me to systems theory. Even before a mentoring relationship had 
begun, I was convinced that studying and intervention with individuals was best done from a systemic point of view. As a student in his class I was informed about the scholarship he was conducting and intrigued by the topics of his research. When he asked if I wanted to volunteer to assist with transcription, I jumped at the opportunity (Lee).

Moments that only took minutes, helped to solidify the relationship I had with my mentor and motivated me, as a student, to see myself as part of the community within the university as opposed to a number. I found that I was most drawn to those professors that showed an honest interest in me and were genuinely interested in my goals and dreams (Jessica).

\section{Beginning of the Relationship}

How does a mentoring relationship start? In a public university with more than 20,000 students, developing a relationship where student and mentor can both benefit from their interaction is essential. First and foremost, students need to understand that the possibility that such a relationship can exist.

During most of my undergraduate degree I searched for a professor/mentor who would take time and invest in my professional and personal development. Most professors passed me over because I was an undergraduate and their focus was on work with graduate students. (John)

Finding the right protégé to mentor is important. While I am interested in the professional and educational development of all of my students, as a mentor, I choose to be selective and look for a very small number of only the most promising undergraduates. Students who are looking for a faculty mentor also are likely selective in the characteristics they expect from a mentor. During the course of my career, I am sure there have been numerous students who have not appreciated my philosophy of education or my personality. As a result of my "person," they looked for other faculty if they were interested in being mentored. I look for students with strong academic potential, an intrinsic desire to learn, a schedule that allows them time to work with me on projects, at least one year left before graduation, and a personality and intellectual interests that mesh well with mine.

Like any relationship, the demonstration of care and interest communicated towards the student is central to faculty-student mentoring. Different students have different needs, and the needs of any one student will change over time. In general, as relationships develop, people disclose more private and personal information about themselves (Altman \& Taylor, 1973). In my own experience, the communication that takes place within mentoring relationships, similarly, deepens as time progresses. While some mentoring 
relationships remain focused primarily on career and academic pursuits, other associations become more personal over time. I frequently assess students I mentor, trying to ascertain what they expect from me, what I can expect from them. In this sense I continue to evaluate students' interests and motivation to continue on and obtain more meaningful experiences. The evaluation of the student's motivation takes place in the context of the ongoing and unique relationship that develops with each student. Mentoring is not a particular set of experiences or a specific body of information that an older wiser person gives to or teaches to all protégés. The essence of mentoring is this strategic relationship that has the possibility for significant personal and academic growth. It is two people bringing together their shared interests along with a desire to learn from each other.

Early communication with mentees is task oriented and academically focused, often centering on courses, minors to take, or career plans. Later, student concerns move to graduation and employment opportunities. Most students lack a basic understanding of career options. The process of finding an internship or evaluating career opportunities leaves undergraduates with numerous unanswered questions. While they may have a general sense that they like "working with people," they do not know where to start when it comes to applying their knowledge and people skills. Given the stage of development of most undergraduates, one can assume that students are in a process of identity formation, that they are to some degree uncertain of the specific people skills they possess and how those can be effectively used within the human service field.

Regardless of the many questions students might raise, their queries primarily deal with issues of identity. Who am I, what unique skills and knowledge do I have, what component of the human service field most interests me, what goals should I set for myself? Significant questions about one's identity take time.

I was able to find that most of my mentor relationships were with faculty that had an "open door mentality". While many of my visits to my faculty mentors were scheduled, my favorite moments seemed to come at spontaneous times, as I'm walking through campus and stopped by his office just to say hello. He asked about my family, my boyfriend, my hopes and dreams for the future, not just professionally but personally. In family studies, we value systems, see the contextual value of our clients, families, and friends. I was understood in the context of my system and environment. An investment was made in all the pieces that made me a person (Jessica).

It was through many conversations in class, coffee shops or over dinner that our personal mentoring relationship turned into a friendship. Individuals must risk being vulnerable in order for change to occur. My mentor's ability to provide a safe mentoring relationship allowed me to be vulnerable and accept challenges in my personal and professional development. These changes snowballed and impacted many different 
aspects of my life. Through this process, I became a more confident and well rounded individual. A vision of my future was developing (John).

I was encouraged beyond my work in the classroom. My mentor was also my faculty advisor for an internship I had at a mental health unit on a local reservation. I was encouraged and complimented about specific skills and knowledge I had as an intern, emphasizing the fact that I brought value to the agency. The relationship helped me understand that mentor/mentee relationships need to be an important dimension of the rest of my life (Jessica).

Given that I mentor academically focused students, questions typically arise about the need for graduate education. Discipline specific concerns as well as why one program might be better than another for a specific student, where these programs exist, as well as when to apply are later student concerns. The fact that graduate assistantships offer significant economical benefits that impact the decision to apply to a certain program is something of which most undergraduates are not aware. Students and their parents are enthusiastic when they hear that graduate school funding is easier to obtain than undergraduate funding. The graduate application process, writing personal statements, letters of reference, admissions interviews, examining the strengths and weaknesses of different programs and the faculty research interests are all useful pieces of information for students applying to graduate schools.

In hindsight, applying to graduate schools without a mentor is too daunting a task. My stress and anxiety were normalized, and the process was enhanced because of my mentor. Having a professional guide me along and help me understand what graduate schools were looking for was very beneficial. He took time out of his personal life to invest in my future. (John)

He inspired me to enter graduate school, offering advice and assistance every step of the way, turning a scary, overwhelming process into a manageable experience. The relationship we formed empowered me to feel confident about my abilities to continue my education and provided me with a strong base for producing quality scholarly work (Lee).

\section{Involvement in the Process of Research}

One method I use to select students arises from an introductory marriage and family course I teach. The course is offered in a large lecture format and examinations are challenging because the course covers such a broad body of information. When talking about marriage and family research I typically discuss some of the more interesting findings from studies I previously have published. For example, I recently showed a videotape of a married couple discussing a relationship issue and then described how I showed participants a video of their heated discussions with their spouses as one component of a marriage education 
program (Long, Angera, Hakoyama, 2006). Understanding the research process is essential in the lives of future practitioners and scholars, as these experiences are one of the primary reasons students later seek out research experiences in their fields of interest (Landrum \& Nelson, 2002). Finding the right students and offering them opportunities to be involved in a program of research is often the beginning of a longer term mentoring relationship.

My professor quickly introduced me to the world of research, taking me in directions I never knew I could go. By listening and reading previous research he had conducted and learning about the current research he was doing, I was intrigued and wanted to be involved. He slowly introduced me to the world of scholarship by teaching me small tasks. I started with transcription, and as my capabilities grew he stayed right on course and continued to challenge me with new tasks, resulting in an entire qualitative research project. It was within the context of this work together that our mentoring relationship evolved (Lee).

In class when I discuss my research I talk about undergraduates who currently are working with me, and the types of activities they are doing. Initially, I do not ask for volunteers directly. By the end of the term I typically have approached one or two students. I ask about their professional and educational goals, and whether or not they are doing volunteer work in the field. If students seem interested in discussing these issues more, I ask them to drop by my office during office hours. I do not set up a specific meeting time because I want students who take initiative and are motivated learners. If students follow up with me, it typically leads to coffee, discussions about research opportunities I currently have, and issues beyond academic concerns.

The meetings outside the university take away the hierarchical dimension of the faculty student relationship. There is a genuine exchange of ideas, not just the idea that the professor knows all and students must listen to learn (Jessica).

While early student research experiences can be tedious and seemingly unimportant, over time, the work grows more meaningful. Early in a mentoring relationship, I strategically give students some of the tedious research tasks, because I want to understand their level of commitment to the process. Some students quickly lose interest in a project and that is fine. Different students have different goals and interests at this stage of their academic careers; I am looking for students with specific interests. There is research that suggests that engaging undergraduate students in research ought to be reserved for those who are committed and dedicated (Evans, Perry, Kras, Gale, \& Campbell, 2009). Although the tasks may be tedious, the importance of those tasks is essential to the final product. For example, accuracy in the time consuming and mundane 
aspect of transcription has significant implications when later analysts are trying to develop an understanding of the data that is grounded in a person's lived experience. While mundane work is initially part of the process, students need to be involved in more than busy work that faculty dislike.

I began by working on transcription which was a wonderful place to start. It benefited me greatly by exposing me to the voices of real people, not just research studies from a textbook. I heard many stories of human triumph and tragedy in the individuals own words, listening to the emotions they were experiencing. This experience gave me a glimpse of what it would be like to listen to clients and understand and accept each individual's story. Transcription was very beneficial to my listening skills, as I had to really hear how individuals were expressing themselves to uncover the emotions they were experiencing without visually seeing the person (Lee).

Students also complete work in collaborative groups, helping each other, learning the same academic processes together. There have been times when my undergraduates were more motivated and competent than the graduate students with whom they were working. As the complexity of the work increases, time spent with a student usually increases and the faculty-student relationship becomes more interdependent. I aim to understand the specific abilities a student might have, or the experiences they would like to have, and then try and provide those opportunities. For students with an interest in family law, I might have them speak to or interview with the intensive probation officer in our county, observing the practice of law and the involvement of the state in the lives of families. For those who demonstrate an affinity for the research process, they may go to professional meetings to meet faculty and students from other institutions. They also might participate in the presentation of a paper at a state or regional meeting. At the end of a semester, the small group of research students and I usually have breakfast at a local restaurant where conversations are more spontaneous and less task oriented.

After I had transcription under my belt I was paired with a graduate student to perform qualitative analyses on one question from the larger study we were working on. This involved learning about free nodes and tree nodes as well as how to use the NVIVO software to identify and classify material. This experience benefited me greatly as it gave me a growing understanding of qualitative research. In addition, it provided me with the confidence to pursue the path I am on and the fire under my belt to do so, knowing that I want and will need to conduct research in my future (Lee).

For students the outcomes from mentoring can be more meaningful than courses they might take. When asking Jessica about the tasks she had undertaken with me, her response was enlightening. 
I don't think so much about the tasks I did, as I think about the opportunities I had. You listened to my ideas and supported them, and when I struggled you helped me out. I was given the opportunity to do research on a project that required my involvement with the Internal Review Board at CMU; I also interviewed subjects, transcribed interviews, and eventually made a professional presentation. While these experiences were priceless in their own ways, the relationship that it fostered between my mentor and me was the higher reward (Jessica).

\section{Reciprocity in Mentoring}

For the faculty-student relationship to flourish, the interaction between faculty and students must benefit both participants. Mentors need not be solely altruistic. Expecting faculty to act in selfless ways with students when there are already excessive demands on faculty is an unrealistic expectation. I am a mentor of undergraduates because the benefits significantly outweigh the costs. Students and faculty both benefit from the exchange.

I imagine the mentoring relationship develops over time as both members encounter different stages in their lives. The mentoring relationship is not one that comes and goes but one that stands the test of time. Although the mentor and mentee will most likely have less contact in the initial phases of the relationship I feel it is always understood that they are there for and support one another. Where I used to go to my mentor for questions pertaining to a class project, in the future I may go to him for questions relating to ethical practices or to review a scholarly article for me. The time may come that the mentor will come to the mentee with a question or dilemma they are facing. The relationship may change in content but the core of the relationship, the respect and trust, will never change (Jessica). I have students helping me with my scholarly activities on a regular basis.

These are people that I learn from, curious people, students who ask questions and raise issues that I might never consider on my own. They learn something about the discipline and the process of research; they put together the proposal to do research with human subjects, analyze data, develop surveys, read and understand scientific literature, interview and transcribe interviews, and assist in the facilitation of marital education programs. These activities are a joint venture. I might have them read a previously approved Internal Review Board (IRB) proposal and then ask them to begin completing an IRB proposal for an upcoming project.

Over the years, numerous faculty members have asked if I pay these students for their work and the answer is no. I do not pay these students for their work because I am convinced that this experience enriches their own academic interests and opportunities. For students, these experiences are a crucial component of their academic identity and impact who they will become as future scholars. For faculty, the relationship allows them assistance in the pursuit of 
their own scholarly endeavors. Earlier in my academic career my own needs were necessarily more self-focused. A program of research, service, leadership responsibilities, and the development of new courses, consumed the majority of my professional time. As time passed and I became established as a professor and researcher, it freed me up to invest more time in the next generation of scholars. My ability to be a productive faculty member greatly was enhanced because I mentored. In the mentoring relationship, students get to do a lot of what they might only read about, or what might be reserved for graduate students. Undergraduates often have lives that are less complex and encumbered than graduate students, and because mentoring opportunities are rare among undergraduatess, they often seem more thankful and excited about the process. With academically focused and motivated students, these experiences often stimulate an intrinsic desire to learn. Students become excited themselves about the process of creating new knowledge.

For me, at a generative stage in my own development, I am reminded of an inspiring comment from Erik Erikson:

A person does best at this time (midlife) to put aside thoughts of death and balance its certainty with the only happiness that is lasting: to increase, by whatever is yours to give, the goodwill and higher order in your sector of the world (Erikson, 1974, P 124).

The typical example of generativity in middle adulthood is parenting one's offspring, socializing, guiding the next generation. The experience of parenting can be fulfilling and unique, providing a feeling that one is caring for the next generation. A similar generative experience can evolve while mentoring undergraduates. As an academician, one's academic "gene pool" can live on. Even now, I clearly see the legacy of my own undergraduate mentor, Barrie Palfreyman, his influence on me impacting the lives of another generation of students.

I expect that I can email or call him at any time. I often send him emails asking for his critiques and comments on research ideas as well as my thesis. I realize that this mentorship is soon going to become part of my network of professionals and has developed a friendship that will continue far into my life and my career. I also have the expectation that I "will pay it forward." Should I someday become a faculty member, I can hopefully foster these types of relationships with my students, allowing the legacy of my mentor to live far beyond his years. Here's to your generativity bank Prof (Jessica).

As I enter my final year of graduate school, I am reminded of the desire to learn and the passion to reach out and help others, characteristics I learned from my mentor. Our friendship holds a special place in my heart and continues to motivate me in the pursuit of helping others. I still lean on my mentor for advice and he still continues to challenge me to think 
outside of the box. What started out as an academic relationship has blossomed into a faithful, authentic friendship (John).

\section{Challenges of Developing Mentoring Relationships within the Academy}

Indeed there are exceptional examples of undergraduates who are mentored by committed faculty. However, the frequency of mentoring undergraduates is limited, partially because mentoring in a university environment is difficult. The academy itself is a system that provides few incentives to mentor or be mentored. While experiences with these students can be intrinsically rewarding, there are few incentives to engage undergraduates outside the classroom. These relationships are not valued when it comes time for promotion or tenure. Grants are not awarded based on mentoring productivity. Decisions about new faculty hires are not based on the new hires experience as a mentor. The academy is not an environment that encourages or rewards mentoring, even if these relationships form the heart of an exceptional educational life changing experience for faculty and students alike. Universities typically bestow awards and recognition to faculty for research productivity and possibly excellence in teaching. As noted earlier, academic mentoring is related to academic achievement, grade point average, school absence, retention rates, satisfaction with the university, time spent on educational pursuits and number of semesters to graduation (Crane, \& Prentice-Dunway, 2007). Academic achievement, satisfaction with the university and high student retention are goals for which most universities strive. Satisfied students are more likely to be involved alumni continuing their involvement and investment in the institution. If the outcomes from academic mentoring help universities achieve their own institutional goals, would it not also be in the best interest of universities to formalize and reward successful faculty mentors?

There has been a small but growing interest in the importance of engaging undergraduate students in academic scholarship. Honors Colleges have for many years offered honors students the opportunity to complete honors theses. Thus, providing undergraduate students with the opportunity for greater student-faculty interaction. More recently, some larger research institutions have begun to offer a limited number of research opportunities to undergraduates as a way of attracting and admitting the most academically gifted students. These practices however are limited, and there is little if any movement within higher education to strategically pursue and encourage the development of faculty-undergraduate student mentoring relationships.

As well as academic departments and faculty, several offices within the student services branch of the university could aid in promoting faculty student mentoring. Admissions, alumni, academic advising offices, and freshmen experience classes that recruit and orient students to the university could advertise and promote opportunities available to work with faculty. Students engaged in serious academic activity with faculty could have the opportunity to have these experiences listed on their transcripts, and included as an accomplishment of their academic majors. If the student voices heard in this paper are representative of a larger population of undergraduates, then academic institutions committed to 
undergraduate education ought to make changes in some of the faculty and student policies noted above. Opportunities for the most gifted students to work more closely on faculty projects could be an elective component of a student's major, increasing their knowledge of and opportunities for mentoring relationships. Tenure and promotion decisions could be changed to include mentoring as an additional criteria by which academicians are evaluated. Faculty must be rewarded, and students encouraged, to pursue a relationship that has the potential for significant academic and professional growth.

\section{Need for Mentoring Outcome Research}

There is a need for additional mentoring research. I have highlighted the importance of a mentoring relationship with undergraduates as a reciprocally beneficial experience within the university. The mentoring relationship itself needs to be studied from student and faculty points of view. If mentoring is a bidirectional relationship then research also must examine the positive outcomes mentoring provides faculty. Research also could examine institutional implications of mentoring undergraduates. A clearer understanding of faculty and institutional benefits might increase faculty involvement, and strengthen university policies that support mentoring. Does mentoring undergraduates actually increase the productivity of faculty? What are those contextual and personal variables that are positively and negatively related to rich mentoring relationships for faculty and students? Is there an empirical intergenerational influence that comes from mentoring relationships? Are faculty who were mentored, more likely to mentor?

One quote that my mentor told me around graduation, that I will never forget was, "You don't have to thank me, just make sure when you are in the position that I am in, that you reach out and do the same thing!" That quote sums up my mentor and the experiences I had as an undergraduate (John).

I recall my mentor saying one day that I should seriously consider becoming a professor. Although I laughed at the time, it was one of the greatest compliments. It let me know that my mentor thought I was strong enough to do what he had done for me, that one day I might impact another student in a way that I had been impacted (Jessica).

\section{Conclusion}

This paper has described the mentoring of undergraduates, highlighting a few of the benefits that come from faculty mentoring undergraduate students during important stages of individual development. Until there is definitive evidence that mentoring is a useful growth producing relationship, faculty, students, and universities likely will verbally affirm mentoring without making any substantive changes in institutional policies. 
Through a very simple action, my mentor was the one that opened the door for my path as a new MFT professional. In thinking of Vygotsky's concept of scaffolding, the ability of a mentor to get involved when afforded the opportunity, but also step back in moments when student's independent abilities can see them through can be a phenomenal gift in the learning process. It builds confidence as a student and ensures that I, as a beginning professional, continue to grow and remain steadfast in my ambitions within the field. At no point have I felt alone in my pursuit for a graduate degree or a career because I feel I have always had the support of my faculty mentors, whether tangibly, or in the back of my mind (Jessica).

In my own personal experience, a simple quote from my mentor in the acknowledgments section of his dissertation reminds me that the reciprocal nature of an intergenerational relationship can change people and greatly enhance their educational experiences.

I want to extend special appreciation to a former mentee, a long-time protégé-turned-mentor, who encouraged me to keep going at critical times in my dissertation process. This has been a special, once-in-a-lifetime experience and an example of how the ideal mentor-protégé relationship really functions (Palfreyman,1992, pp.7). 


\section{References}

Altman, I. \& Taylor, D. (1973). Social penetration: The development of interpersonal relationships. New York: Holt.

Cosgrove, T.J. (1986). The effects of participation in a mentoring-transcript program on freshmen. Journal of College Student Personnel. 27, 199-124.

Cramer, R.J., \& Prentice-Dunn, S. (2007). Caring for the whole person: Guidelines for advancing undergraduate mentorship. College Student Journal, 41(4), 771-778.

DuBois, D. L., \& Karcher, M.A. (Eds). (2005). Handbook of youth mentoring. Thousand Oaks, CA: Sage.

Eby, L. T. (1997). Alternative forms of mentoring in changing organizational environments: A conceptual extension of the mentoring literature. Journal of Vocational Behavior, 51, 125-144.

Eby, L.T., Allen, T.D., Evans, S.C., Ng, T., \& DuBois, D.L. (2008). Does mentoring matter? A multidisciplinary meta-analysis comparing mentored and non-mentored individuals. Journal of Vocational Behavior, 72, 254267.

Erikson, E.H. (1974). Dimensions of a New Identity.New York: Norton.

Evans, S. E., Perry, A. R., Kras, A., Gale, E. B., \& Campbell, C. (2009). Supervising and mentoring undergraduates: A graduate student perspective. The Behavior Therapist, 32(4), 77-82.

Johnson, W. B. (2007). Student-faculty mentorship outcomes. In T.D. Allen \& L. T. Eby (eds.), Blackwell handbook of mentoring (pp.189-210). Oxford:Blackwell.

Kardash, C.M. (2000). Evaluation of an undergraduate research experience: Perceptions of undergraduate interns and their faculty mentors. Journal of Educational Psychology, 92, 191-201.

Landrum, R.E., \& Nelsen, L.R. (2002). The undergraduate research assistantship: An analysis of the benefits. Teaching of Psychology, 29, 15-19.

Levinson, D.J., Darrow, D., Levinson, M., Klein, E.B, \& McKee, B. (1978). Seasons of a man's life. New York: Academic Press. 
Long, E. C. J., Angera, J. J., \& Hakoyama, M. (2006). Using videotaped feedback during intervention with married couples: A qualitative assessment. Family Relations, 55, 428-438.

Palfreyman, Barrie J. (1992). Mentoring among key administrators in undergraduate theological colleges in Canada. Retrieved from Dissertations \&Theses: Full Text.(Publication No. AAT 9231341).

Ragins, B.R. (2002). Understanding diversified mentoring relationships: Definitions, challenges and strategies. In D. Clutterbuck \& B.R. Regins (Eds.), Mentoring and diversity: An international perspective (pp. 23-53). Oxford: Butterworth.

Sperber, M. (2000). Beer and Circus: How big-time college sports is crippling undergraduate education. New York: Henry Holt Co.

Wooden, J., Yaeger, D., Maxwell, J. (2009). A game plan for life: The power of mentoring. New York: Bloomsbury. 